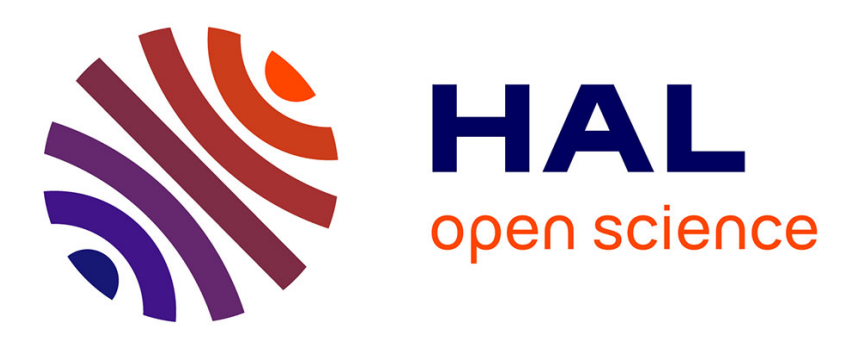

\title{
Investigation of the graft length impact on the interfacial toughness in a cellulose/poly( $\epsilon$-caprolactone) bilayer laminate
}

Hanna Lönnberg, Linda Fogelström, Qi Zhou, Anders Hult, Lars Berglund, Eva Malmström

\section{To cite this version:}

Hanna Lönnberg, Linda Fogelström, Qi Zhou, Anders Hult, Lars Berglund, et al.. Investigation of the graft length impact on the interfacial toughness in a cellulose/poly ( $\epsilon$-caprolactone) bilayer laminate. Composites Science and Technology, 2010, 71 (1), pp.9. 10.1016/j.compscitech.2010.09.007 . hal00702322

\section{HAL Id: hal-00702322 \\ https://hal.science/hal-00702322}

Submitted on 30 May 2012

HAL is a multi-disciplinary open access archive for the deposit and dissemination of scientific research documents, whether they are published or not. The documents may come from teaching and research institutions in France or abroad, or from public or private research centers.
L'archive ouverte pluridisciplinaire HAL, est destinée au dépôt et à la diffusion de documents scientifiques de niveau recherche, publiés ou non, émanant des établissements d'enseignement et de recherche français ou étrangers, des laboratoires publics ou privés. 


\section{Accepted Manuscript}

Investigation of the graft length impact on the interfacial toughness in a cellulose/poly( $\varepsilon$-caprolactone) bilayer laminate

Hanna Lönnberg, Linda Fogelström, Qi Zhou, Anders Hult, Lars Berglund, Eva Malmström

PII: S0266-3538(10)00352-0

DOI: 10.1016/j.compscitech.2010.09.007

Reference: CSTE 4810

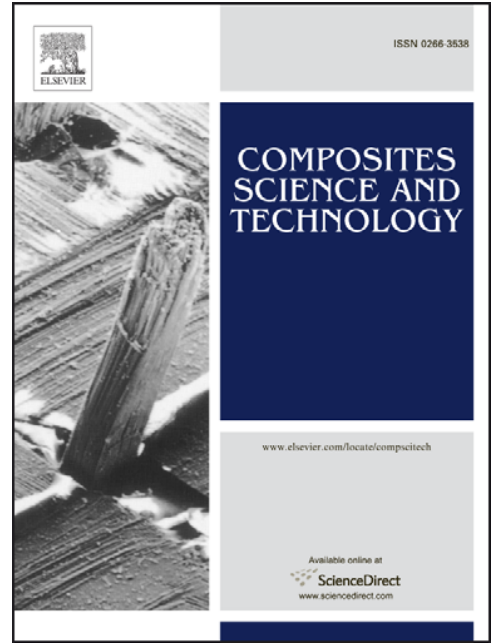

To appear in:

Composites Science and Technology

Received Date:

26 March 2010

Revised Date:

8 September 2010

Accepted Date:

13 September 2010

Please cite this article as: Lönnberg, H., Fogelström, L., Zhou, Q., Hult, A., Berglund, L., Malmström, E., Investigation of the graft length impact on the interfacial toughness in a cellulose/poly( $\varepsilon$-caprolactone) bilayer laminate, Composites Science and Technology (2010), doi: 10.1016/j.compscitech.2010.09.007

This is a PDF file of an unedited manuscript that has been accepted for publication. As a service to our customers we are providing this early version of the manuscript. The manuscript will undergo copyediting, typesetting, and review of the resulting proof before it is published in its final form. Please note that during the production process errors may be discovered which could affect the content, and all legal disclaimers that apply to the journal pertain. 


\section{Investigation of the graft length impact on the}

\section{interfacial toughness in a cellulose/poly( -}

\section{caprolactone) bilayer laminate}

Hanna Lönnberg, Linda Fogelström, Qi Zhou, Anders Hult, Lars Berglund, and Eva Malmström*

Royal Institute of Technology, Fibre and Polymer Technology

Teknikringen 56-58, SE-100 44 Stockholm, Sweden

*corresponding author: mavem@kth.se, Tel: +46 (0)8 7907225, Fax: +46 (0)8 7908283

\section{ABSTRACT}

Interfacial adhesion between immiscible cellulose-polymer interfaces is a crucial property for fibrous biocomposites. To tailor the interfacial adhesion, the grafting of polymers from cellulose films was studied using ring-opening polymerization of -caprolactone. The poly( -caprolactone) (PCL) grafted cellulose was analyzed with FTIR, AFM and via water CA measurements. The graft length was varied by the addition of a free initiator, enabling tailoring of the interfacial toughness. Films of microfibrillated cellulose were grafted with PCL and hot-pressed together with a PCL film to form a bilayer laminate. Interfacial peeling toughness correlates very strongly with PCL degree of polymerization (DP). PCL 
grafts form physical entanglements in the PCL matrix and promote significant plastic deformation in the PCL bulk, thus increasing interfacial peeling energy.

KEYWORDS: microfibrillated cellulose grafted with polycaprolactone
A. Polymer-matrix composites

A. Laminate

A. Wood

B. Interfacial strength

B. Delamination

\section{INTRODUCTION}

Cellulose in the form of high-strength nanofibers is the main load-bearing constituent in the cell wall of plant structures. The biosynthetic origin combined with exceptional physical properties and nanoscale lateral dimension makes cellulose a highly desirable constituent in new nanostructured material systems such as nanopaper, ${ }^{1}$ aerogels, ${ }^{2}$ biofoams, ${ }^{3}$ and high-strength biocomposites. ${ }^{4}$

Fibrous plant cells, typically $30 \mu \mathrm{m}$ in diameter and several $\mathrm{mm}$ in length, are already used as reinforcement in biocomposite materials. ${ }^{5}$ Such systems are very complex, and their end properties are difficult to predict. However, one of the most important issues for fully taking advantage of the excellent mechanical properties of cellulosic plant fibers in composite materials, is the creation of a strong interfacial adhesion between the reinforcing fiber and the polymer matrix. ${ }^{6}$ Different approaches have been utilized to improve fiber dispersion as well as strengthen the interface between fiber and matrix e.g. fiber-surface 
modification attaching silanes, isocyanates etc. to the hydroxyl group on the surface of cellulose. ${ }^{7,8}$ There are also a number of studies on the improvement of the mechanical properties by grafting polymers to or from the cellulose surface. ${ }^{90-12}$

The effect of chain entanglements on the interfacial toughness has been reviewed by Creton et al. ${ }^{13}$ At high areal density of high molar mass polymer molecules crossing an immiscible interface, entanglements can be highly successful during interface separation and promote extensive plastic deformation in polymer regions surrounding the interface. As a consequence, significant improvement in the interfacial toughness can be achieved. ${ }^{14}$

In the present study, we use the ideas reviewed by Creton et al. for fracture of interfaces between immiscible polymers, ${ }^{13}$ and apply them to the equally immiscible interface between cellulose nanofibers and a polymer matrix. For this reason, we graft PCL chains of various chain lengths from the cellulose surface in a step towards molecular design of grafts for interfacial toughness. High interface toughness often enhances composites strength; however, low toughness of the fiber/matrix interface may also be advantageous in certain fibrous polymer composites. Extensive fiber pull-out is then promoted, and consumes considerable energy so that composite toughness is increased. ${ }^{15}$

We have previously confirmed that ring-opening polymerization (ROP) is a versatile technique in order to covalently graft polymers directly from cellulose substrates, via a grafting-from approach. ${ }^{16,17}$ Surface characterizations of the PCL-grafted substrates with different graft lengths, as well as various prefunctionalization of the cellulosic surfaces, have shown significant impact on the surface composition, the surface morphology as well as the hydrophobic properties. ${ }^{16}$ In addition, for PCL-grafted nanosized cellulose, longer grafts gradually improved the dispersion in non-polar solvent and showed a gradual change 
in the thermal properties and in the crystallization behavior of the PCL grafts, which verified an increase in graft length with higher target DP, i.e., ratio of added monomer to initiator. Habibi et al. ${ }^{11}$ studied nanocomposite materials reinforced with different compositions of PCL-grafted cellulose nanocrystals that were obtained via a grafting-from approach. They reported a significant improvement in mechanical properties of biocomposites based on PCL-grafted cellulose nanocrystals in comparison to neat cellulose nanocrystals. However, no investigation of the graft length impact on the mechanical properties was performed.

In the present study PCL of different molecular weights is grafted from a cellulose surface and thereafter we analyze the effect of graft length on the interfacial adhesion in a bilayer laminate. The aim is to investigate if chain entanglements across a PCL grafted cellulose fiber/ polymer matrix interface can be utilized to strengthen the interfacial toughness between the reinforcement and the matrix in a biocomposite material.

\section{EXPERIMENTAL}

Materials. $\varepsilon$-Caprolactone $(\varepsilon-\mathrm{CL})$, benzyl alcohol, tin octoate $\left(\mathrm{SnOct}_{2}\right)$, tetrahydrofuran (THF), methanol (MeOH) and poly(e-caprolactone) (PCL) (Sigma-Aldrich, MW 80000 $\mathrm{g} / \mathrm{mol}$ ) were used as received. Microfibrillated cellulose films (MFC-films) were prepared according to a procedure described by Henrikssson et al. ${ }^{1}$ The MFC-films were dried in vacuum oven at $50^{\circ} \mathrm{C}$ for $24 \mathrm{~h}$ prior to use.

Characterization. Nuclear magnetic resonance (NMR) spectra were recorded at $400 \mathrm{MHz}$ on a Bruker $\mathrm{AM} 400$ using $\mathrm{CDCl}_{3}$ as solvent. The TMS signal was used as an internal standard. Fourier transform infrared spectroscopy (FTIR) was performed on a Perkin-Elmer 
Spectrum 2000 FTIR equipped with a MKII Golden Gate, Single Reflection ATR system from Specac Ltd, London, U.K. All spectra were normalized against a specific ATR crystal adsorption. Size exclusion chromatography (SEC) of the free, ungrafted, polymer formed was performed using a TDA Model 301 equipped with one or two $\mathrm{GMH}_{\mathrm{HR}}-\mathrm{M}$ columns with TSK-gel (Tosoh Biosep), a VE 5200 GPC Autosampler, a VE 1121 GPC Solvent pump and a VE 5710 GPC Degasser, from Viscotek Corp. THF was used as the mobile phase (1.0 ml $\left.\min ^{-1}\right)$. The measurement was performed at $35^{\circ} \mathrm{C}$. The SEC apparatus was calibrated with linear polystyrenes standards, and toluene was used as flow rate marker. Peel tests were performed on a dynamic mechanical analysis (DMA) TA-instrument Q800 equipped with a film fixture for tensile testing. The measurements were performed on rectangular laminates samples $(20 \mathrm{x} 4 \mathrm{~mm})$ at room temperature. The tests were performed in a controlled stressstrain mode with a preload force of $0.0010 \mathrm{~N}$ and force ramp of $0.100 \mathrm{~N} / \mathrm{min}$. The instrument set-up allowed for a maximum displacement of $20 \mathrm{~mm}$. Four samples were used to characterize each PCL-MFC laminate. Atomic Force Microscopy (AFM) was performed using a Nanoscope III-a system (Digital Instruments) equipped with an $E V$-type vertically engaged piezoelectric scanner operating in tapping mode in air. Silicon AFM probes from Veccon (Nanosensors) were used with a resonance frequency of 275-348 kHz.

Synthesis of MFC-films grafted with PCL (MFC-PCL). In total, six different samples of the MFC-films were prepared: blank and MFC-PCL with target DP 75, 150, 300, and 600. The target DP was based on the amount of monomer, $\varepsilon-\mathrm{CL}$, and the initiator, benzyl alcohol, added to the systems. The polymerizations were performed similarly to previously described procedures. ${ }^{16,17}$ Pre-dried MFC-films (2 pieces of $2 * 3 \mathrm{~cm}^{2}$ and 1 piece of $2 * 1 \mathrm{~cm}^{2}$ ) were immersed in $\varepsilon$-CL (12 g) and toluene $(20 \mathrm{ml})$. Thereafter benzyl alcohol was added to 
the solution, corresponding to the targeted DP. To remove a majority of the remaining water, part of the solvent $(15 \mathrm{ml})$ was distilled off before the catalyst, $\mathrm{Sn}(\mathrm{Oct})_{2}(0.36 \mathrm{~g})$, was added to the system under argon flow at $100{ }^{\circ} \mathrm{C}$. The polymerizations were allowed to proceed16-18 h. Subsequently, the free PCL was dissolved in THF and precipitated in cold $\mathrm{MeOH}$. In order to remove physically adsorbed but ungrafted PCL, the PCL grafted MFC films were thoroughly washed using soxhlet extraction in THF before characterization. The blank sample was treated in the same manner as the other samples with the exception that no catalyst was added in the ROP step.

Preparation of PCL-film and PCL-MFC bilayer laminates. PCL-films were prepared by solvent casting from THF. The bilayer laminates of MFC-PCL films and PCL-films were prepared by hot-pressing at $120^{\circ} \mathrm{C}, 2 \mathrm{~min} 1$ unit pressure and then 5 min 4 unit pressure.

\section{RESULTS AND DISCUSSION}

In this study ring-opening polymerization (ROP) is performed to graft poly $(\varepsilon-$ caprolactone) (PCL) from a film of microfibrillated cellulose (MFC) derived from wood pulp. ${ }^{1}$ Subsequently, the PCL-grafted MFC films (MFC-PCL), are hot-pressed together with neat PCL film to form a PCL-MFC bilayer laminate. During the hot press stage the grafted molecules can diffuse across the interface.

In an attempt to gradually improve the interfacial peeling toughness of the PCL-MFC laminates the MFC-films were grafted with PCL to several different polymer lengths. We have previously demonstrated that the length of the polymer grafts, and the graft layer thickness, can be varied by the addition of a free (sacrificial) initiator (benzyl alcohol) to the polymerization mixture in a grafting-from approach, Scheme $1 .^{16,17}$ The sacrificial 
initiator also gives rise to a free polymer that can be isolated and subsequently characterized.

The samples prepared in this study are outlined in Table 1 . The molar masses of the ungrafted, free PCL formed during ROP were determined by SEC and ${ }^{1} \mathrm{H}$ NMR spectroscopy. The determined molar masses $\left(\mathrm{M}_{\mathrm{n}}\right)$, and corresponding (DP), were found to be lower than the theoretical values. This is somewhat expected since the ROP is initiated both from the added free initiator as well as from available OH-groups on the cellulose surface. However, the estimated molar masses of the free PCL were found to increase with increasing monomer-to-initiator ratio, i.e. target DP, Table 1.

FTIR spectroscopy was used to compare the amount of grafted PCL on the MFC-film surfaces for the different targeted DPs, Figure 1. In agreement with the previous studies ${ }^{16,17}$ a gradually increasing peak intensity of the carbonyl peak (at $1725 \mathrm{~cm}-1$ ) was observed for higher target DP, thus indicating that more polymer is bound to the surface when higher DPs were targeted, which is also in agreement with the results from the characterization of the free, ungrafted PCL analyzed via ${ }^{1} \mathrm{H}-\mathrm{NMR}$ and SEC analysis.

Atomic force microscopy (AFM) was used to study the change in surface morphology due to grafting, Figure 2. The MFC-film shows a defined fibrillar structure, whereas the images of MFC-PCL reveal an increasingly more polymer-covered surface with less defined fibrillar structure. Thus, there is a good agreement between the results from the FTIR analysis and the AFM images that indicate a gradual increase of the grafted polymer layers, or graft lengths, on the MFC-film surfaces with higher target DPs.

Contact angle (CA) against water was measured to investigate the change in hydrophobicity of the MFC-films as an effect of the grafting of PCL from the surface, 
Table 1. It can be observed that the PCL grafting increased the hydrophobicity of all MFCfilms. The MFC-PCL75 to MFC-PCL300 exhibits similar CA (91-94º, whereas a significantly higher CA was observed for the MFC-PCL600 $\left(105^{\circ}\right)$. Thus, all CAs of the PCL-grafted MFC-films are significantly higher than for both the reference materials, PCL and casted MFC-films. So despite the fact that the longer PCL grafts have a more smoothening effect on the surface morphology, observed with AFM, the higher surface coverage of hydrophobic PCL in combination with the present of surface roughness is accompanied by a higher hydrophobicity. The results are in good agreement with a previous study of PCL-grafted filter papers ${ }^{16}$ where high surface coverage of PCL grafts, obtained after pre-functionalization and grafting with long PCL grafts, significantly increased the CA to $105^{\circ}$ for the PCL-grafted filter paper surface.

The graft length impact on the interfacial toughness in a bilayer laminate of the PCL grafted MFC-films was evaluated in a peel test, using a DMA instrument. The MFC-PCL films with different target DPs were laminated against thin films of pure PCL-forming bilayer laminates, which thereafter were subjected to the peel test. Figure 3 presents the peeling energy as a function of displacement; the values are also reported in Table 1. As seen, the sample grafted with short PCL chains, MFC-PCL75, does not show any improvement of the interfacial adhesion as compared to the neat MFC-film. This suggests that albeit the hydrophobicity of the surface is increased, as verified by CA measurements, the grafts are too short to substantially affect the interfacial adhesion. The samples MFCPCL150 to MFC-PCL600, however, require a significantly higher peeling energy. Since the energy is very high, plastic deformation in the PCL matrix is the only plausible explanation caused by significant contribution from chain entanglements. In addition, interfacial 
peeling toughness correlates very strongly with increasing chain length of PCL. This clearly demonstrates the importance of physical entanglements to promote plastic deformation in the PCL layer, and this represents the first study where the potential of this approach is demonstrated for cellulose-polymer interfaces. Herein the engineering of interfacial toughness at cellulose-polymer interfaces has been demonstrated and may be extended to other polymer systems. The demonstration is of great significance for cellulose biocomposite materials, since the laminate can be viewed as a model for fiber/matrix and nanofiber/matrix interfaces. Furthermore, we anticipate a highly durable interface bond in moist environments due to the grafted molecules and the corresponding physical entanglements in the interphase region.

\section{CONCLUSION}

In the present work, grafting impenetrable cellulose fiber surfaces with polymer chains was demonstrated as a tool for tailoring the interfacial adhesion in a bilayer laminate due to the formation of physical entanglements between chains in the matrix and on the surface. A grafting-from approach was utilized to covalently graft the MFC-films with PCL to different target DPs (MFC-PCL), controlled by the addition of a free initiator. Characterization of the ungrafted PCL and PCL-grafted MFC films showed an increase in the molecular weight, and the graft layer thickness, with higher target DP. The MFC-PCL films were hot-pressed together with thin PCL-films to form bilayer laminates, which thereafter was subjected to peel tests in order to investigate the effect of graft length on the interfacial adhesion in the bilayer laminate. The peel test revealed a significant impact of the graft length on the interfacial adhesion, and an increase in the molecular weight of the PCL grafts required a gradually increase in the peeling energy for a delamination of the 
bilayer laminate. Thus, the formation of entanglements across the immiscible cellulose/PCL interface promotes plastic shear yielding in the bulk polymer layer and therefore dramatically enhances interfacial toughness of the immiscible interface studied.

Acknowledgement. Swedish Agency for Innovation Systems (VINNOVA) and Swedish

Center for Biomimetic Fiber Engineering (BIOMIME) are thanked for financial support.

M. Ankerfors at Innventia AB, Sweden, is thanked for providing the MFC.

\section{REFERENCES}

1. Henriksson, M.; Berglund, L. A.; Isaksson, P.; Lindström, T.; Nishino, T. Cellulose Nanopaper Structures of High Toughness. Biomacromolecules 2008. 9(6): 15791585.

2. Paakko, M.; Vapaavuori, J.; Silvennoinen, R.; Kosonen, H.; Ankerfors, M.; Lindström, T.; Berglund, L. A.; Ikkala, O. Long and entangled native cellulose I nanofibers allow flexible aerogels and hierarchically porous templates for functionalities. Soft Matter 2008. 4(12): 2492-2499.

3. Svagan, A. J.; Samir, M. A. S. A.; Berglund, L. A. Biomimetic foams of high mechanical performance based on nanostructured cell walls reinforced by native cellulose nanofibrils. Adv Mater. 2008. 20(7): 1263-1269.

4. Yano, H.; Sugiyama, J.; Nakagaito, A. N.; Nogi, M.; Matsuura, T.; Hikita, M.; Handa, K. Optically transparent composites reinforced with networks of bacterial nanofibers. Adv. Mater. 2005. 17(2): 153-155.

5. Mohanty, A. K.; Misra, M.; Hinrichsen, G. Biofibres, biodegradable polymers and biocomposites. An overview. Macromol. Mater. Eng. 2000. 276/277: 1-24.

6. Riedel, U.; Nickel, J. Natural fibre-reinforced biopolymers as construction materials. New discoveries. Angew. Makromo. Chem. 1999. 272: 34-40.

7. Bledzki, A. K.; Gassan, J. Composites reinforced with cellulose based fibres. J. Prog Polym. Sci. 1999. 24(2): 221-274.

8. Trejo-O'Reilly, J.-A.; Cavaille, J.-Y.; Gandini, A. The surface chemical modification of cellulosic fibers in view of their use in composite materials. Cellulose 1997. 4(4): 305-320.

9. Joly, C.; Gauthier, R.; Chabert, B. Physical chemistry of the interface in polypropylene/cellulosic-fiber composites. Compos. Sci. Technol. 1996. 56(7): 761765. 
10. Belgacem, M. N.; Gandini, A. The surface modification of cellulose fibres for use as reinforcing elements in composite materials. Compos. Interfaces 2005. 12(1-2): 41-75.

11. Habibi, Y.; Goffin, A.-L.; Schiltz, N.; Duquesne, E.; Dubois, P.; Dufresne, A. Bionanocomposites based on poly( -caprolactone)-grafted cellulose nanocrystals by ring-opening polymerization. J. Mater. Chem. 2008. 18(41): 5002-5010.

12. Samir, M. A. S. A.; Alloin, F.; Dufresne, A. Review of Recent Research into Cellulosic Whiskers, Their Properties and Their Application in Nanocomposite Field. Biomacromolecules 2005. 6(2): 612-626.

13. Creton, C.; Kramer, E. J.; Brown, H. R.; Hui, C.-Y. Adhesion and fracture of interfaces between immiscible polymers: from the molecular to the continuum scale. Adv. Polym. Sci. 2002. 156(Molecular Simulation Fracture Gel Theory): 53136.

14. Gurumurthy, C.; Kramer, E.; Hui, C.-Y. Controlling Interfacial Interpenetration and Fracture Properties of Polyimide/Epoxy Interfaces. J. Adhes. 2006. 82(3): 239-266.

15. Kelly, A., Proc. R. Interface Effects and the Work of Fracture of a Fibrous Composite. Proc.s of Roy. Soc. of London. Series A, Math. Phys. Sci. 1970; 95.

16. Lönnberg, H.; Zhou, Q.; Brumer, H.; Teeri Tuula, T.; Malmström, E.; Hult, A. Grafting of cellulose fibers with poly( -caprolactone) and Poly(L-lactic acid) via ring-opening polymerization. Biomacromolecules, 2006. 7(7): 2178-85.

17. Lönnberg, H.; Fogelström, L.; Berglund, L.; Malmstöm, E.; Hult, A. Surface grafting of microfibrillated cellulose with poly( -caprolactone) - Synthesis and characterization. Eur. Polym. J. 2008. 44(9): 2991-2997. 


\section{Table Caption}

Table 1. Characterization of ungrafted PCL formed during ROP of -CL, contact angle of the PCL grafted MFC-films, and results from the peel test of the bilayer laminate.

\section{Scheme Caption}

Scheme 1. ROP of -CL from the MFC-film surface using benzyl alcohol as free initiator.

\section{Figure Captions}

Figure 1. FTIR spectra of blank MFC-film and MFC-films grafted with different target DP of PCL.

Figure 2. AFM images of reference MFC-film (A), MFC-PCL150 (B), MFC-PCL600 (C).

The images are $1.5 \times 1.5 \mu \mathrm{m}^{2}$.

Figure 3. Interfacial peeling energy (toughness) of bilayer laminates prepared by joining MFC-PCL film with a PCL film. 
Table 1.

\begin{tabular}{|c|c|c|c|c|c|c|}
\hline Sample & $\begin{array}{l}\text { Theo.MW } \\
(\mathrm{g} / \mathrm{mol}) \\
\left(\mathrm{DP}_{\text {theo }}\right)\end{array}$ & $\begin{array}{l}\text { SEC } \\
\mathrm{Mn}(P D I)^{\mathrm{b}} \\
(\mathrm{g} / \mathrm{mol}) \\
\left(\mathrm{DP}_{\mathrm{SEC}}\right)\end{array}$ & $\begin{array}{l}\text { NMR } \\
\text { Mn (conv) } \\
(\mathrm{g} / \mathrm{mol}, \%) \\
\left(\mathrm{DP}_{\mathrm{NMR}}\right)\end{array}$ & $\begin{array}{l}\mathrm{CA} \\
\mathrm{CA}(\mathrm{std})^{\mathrm{d}} \\
\left(^{\circ}\right)\end{array}$ & $\begin{array}{l}\text { Peel test }{ }^{\mathrm{e}} \\
\text { Displacement }^{\mathrm{f}} \\
(\mathrm{mm})\end{array}$ & $\begin{array}{l}\text { Peel test }^{\mathrm{e}} \\
\text { Peeling } \\
\text { energy (std) } \\
\left(\mathrm{J} / \mathrm{m}^{2}\right)\end{array}$ \\
\hline MFC-film & - & - & - & $67( \pm 2)$ & 15.0 & $14.9(4.2)$ \\
\hline MFC-PCL75 & $\begin{array}{l}8700 \\
(75)\end{array}$ & $\begin{array}{l}7900(1.2) \\
(69)\end{array}$ & $\begin{array}{l}6700(91) \\
(59)\end{array}$ & $91( \pm 1)$ & 17,5 & $15,3(4.4)$ \\
\hline MFC-PCL150 & $\begin{array}{l}17200 \\
(150)\end{array}$ & $\begin{array}{l}10000(1.2) \\
(88)\end{array}$ & $\begin{array}{l}7750(93) \\
(68)\end{array}$ & $\pm 2)$ & 20.0 & $41.7(11.6)$ \\
\hline MFC-PCL300 & $\begin{array}{l}34300 \\
(300)\end{array}$ & $\begin{array}{l}12200(1.3) \\
(107)\end{array}$ & $\begin{array}{l}9700(91) \\
(85)\end{array}$ & $94( \pm 1)$ & 20.0 & $52.8(11.8)$ \\
\hline MFC-PCL600 & $\begin{array}{l}68500 \\
(600)\end{array}$ & $\begin{array}{l}22200(1.4) \\
(195)\end{array}$ & $\begin{array}{l}17400(94) \\
(150)\end{array}$ & $105( \pm 3)$ & 20.0 & $64.9(21.2)$ \\
\hline PCL-film & - & 7 & - & $84( \pm 1)$ & - & \\
\hline
\end{tabular}

a) Theoretical molecular weight (MW) and degree of polymerization $\left(\mathrm{DP}_{\text {theo }}\right)$ was calculated by $[\mathrm{M}] /[\mathrm{I}]_{\text {free }}$, b) $\mathrm{Mn}$ = number average molecular weight; PDI = polydispersity index as determined by size exclusion chromatography, and degree of polymerization $\mathrm{DP}_{\mathrm{SEC}}$. c) $\mathrm{Mn}$ $=$ number average molecular; conv $=$ monomer conversion, degree of polymerization $\mathrm{DP}_{\mathrm{NMR}}$ calculated from ${ }^{1} \mathrm{H}$ NMR spectroscopy. d) water contact angle with standard deviation in brackets. e) results from the peel test of the bilayer laminates prepared from the PCL grafted MFC films and neat PCL films. f) The instrument set-up allowed for a maximum displacement of $20 \mathrm{~mm}$. 
Scheme 1.
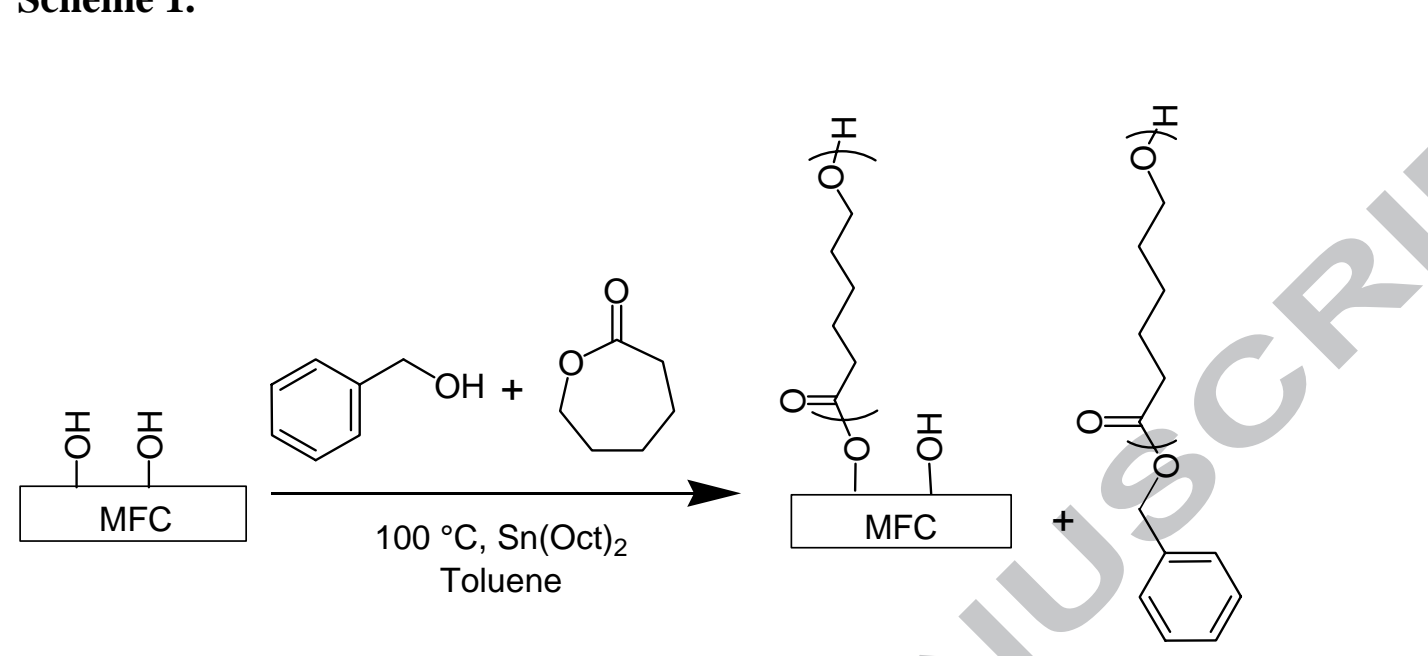
Figure 1.

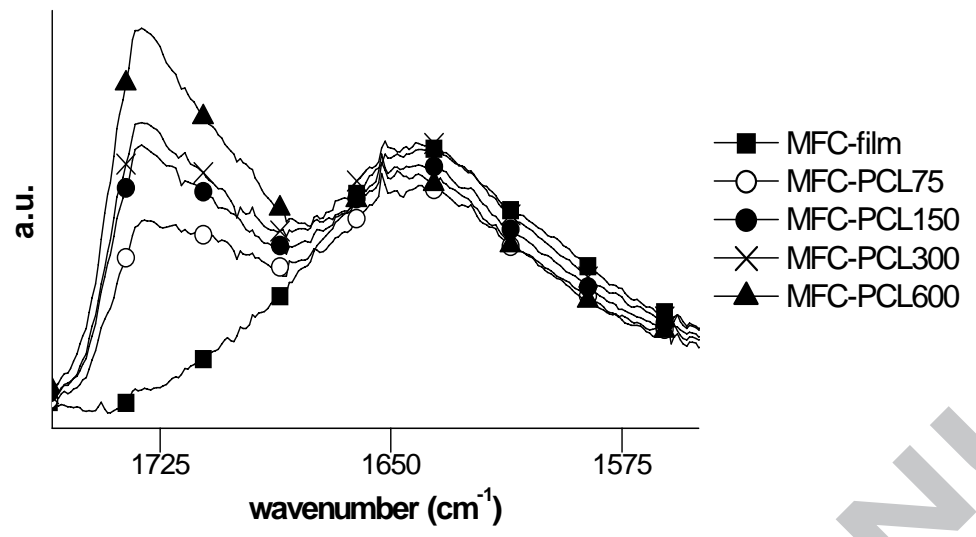


Figure 2.
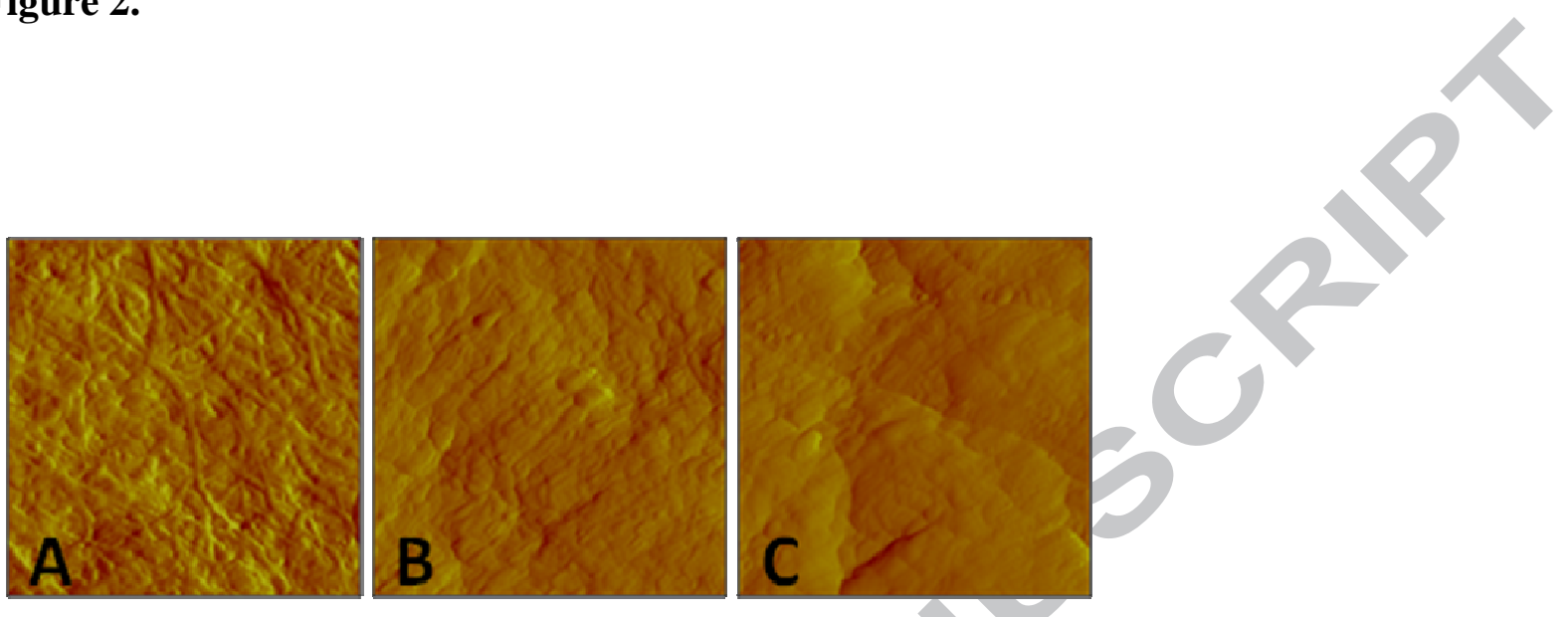


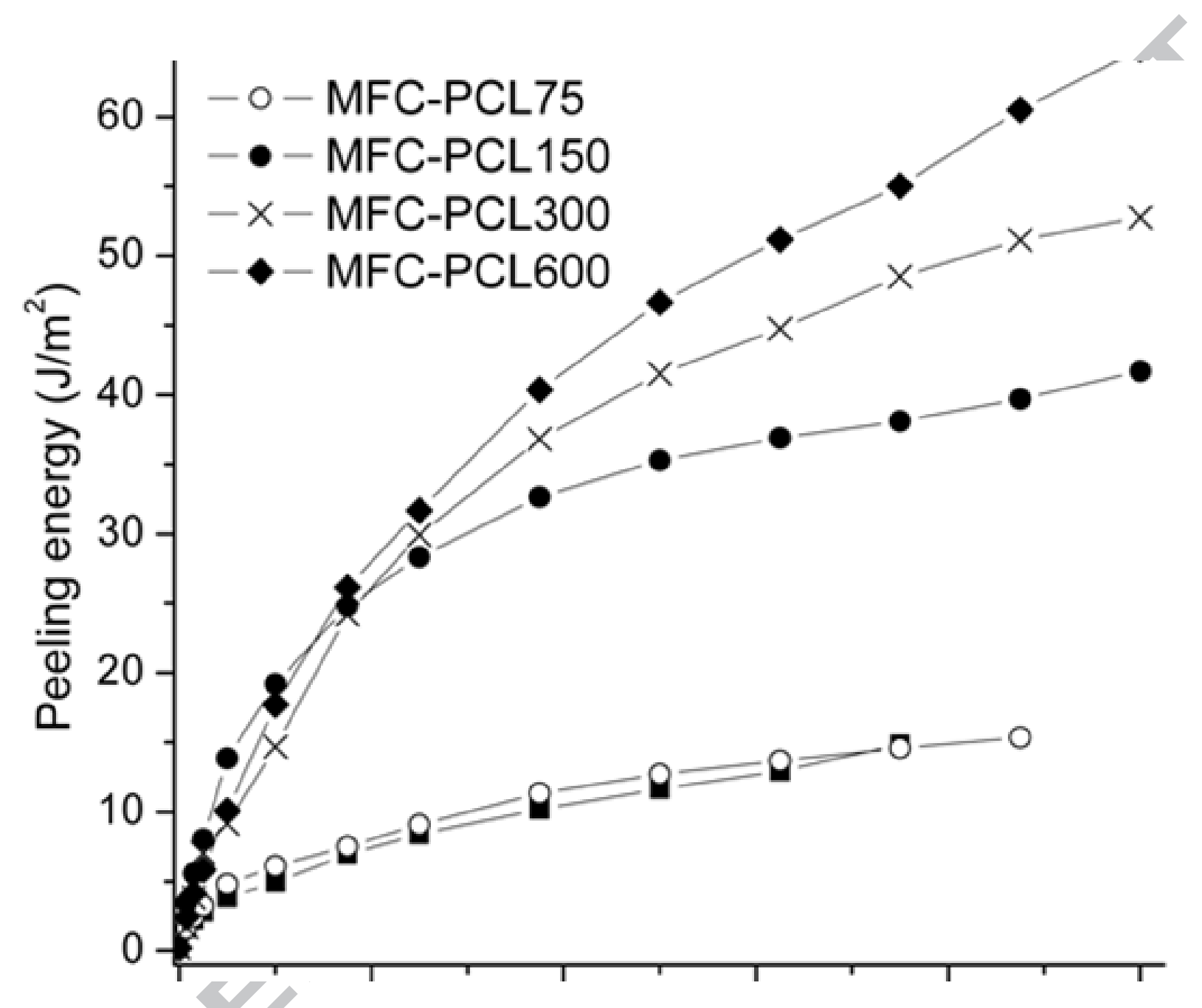




\begin{tabular}{|c|c|c|c|c|c|c|}
\hline Sample & $\begin{array}{l}\mathrm{MW}^{\mathrm{a}} \\
(\mathrm{g} / \mathrm{mol})\end{array}$ & $\begin{array}{l}\text { SEC } \\
\text { Mn (PDI) }{ }^{b, c} \\
(\mathrm{~g} / \mathrm{mol})\end{array}$ & $\begin{array}{l}\text { NMR } \\
\text { Mn (conv) } \\
b, d \\
(\mathrm{~g} / \mathrm{mol}, \%)\end{array}$ & $\begin{array}{l}\text { Contact } \\
\text { angle } \\
\text { CA (std) } \\
\left({ }^{\circ}\right)\end{array}$ & $\begin{array}{l}\text { Peel test }{ }^{\mathrm{f}} \\
\text { Displacemen } \\
\mathrm{t}^{\mathrm{g}} \\
(\mathrm{mm})\end{array}$ & $\begin{array}{l}\text { Peel test }{ }^{\mathrm{f}} \\
\text { Peeling } \\
\text { energy (std) } \\
\left(\mathrm{J} / \mathrm{m}^{2}\right)\end{array}$ \\
\hline MFC-film & - & - & - & $67( \pm 2)$ & 15.0 & 14.9 (4.2) \\
\hline \begin{tabular}{|l|} 
MFC- \\
PCL 75 \\
\end{tabular} & 8700 & $7900(1.2)$ & $6700(91)$ & $91( \pm 1)$ & 17.5 & $15,3(4.4)$ \\
\hline $\begin{array}{l}\text { MFC- } \\
\text { PCL150 }\end{array}$ & 17200 & $10000(1.2)$ & $7750(93)$ & $93( \pm 2)$ & 20.0 & $41.7(11.6)$ \\
\hline $\begin{array}{l}\text { MFC- } \\
\text { PCL300 }\end{array}$ & 34300 & $12200(1.3)$ & $9700(91)$ & $94( \pm 1)$ & 20.0 & $52.8(11.8)$ \\
\hline $\begin{array}{l}\text { MFC- } \\
\text { PCL600 }\end{array}$ & 68500 & $22200(1.4)$ & $17400(94)$ & $105( \pm 3)$ & 20.0 & $64.9(21.2)$ \\
\hline PCL-film & . & - & - & $84( \pm 1)$ & - & \\
\hline
\end{tabular}

